\title{
COMPARISON OF INFORMATION VALUE OF DIFFERENT METHODS OF STUDY IN DIAGNOSIS OF
} SECONDARY NEOVASCULARIZED GLAUCOMA

\section{Bezdetko P. A., Bezkorovaina I. N., Duras I. G.}

Kharkiv, Poltava, Ukraine

The article presents results of examination of patients with different stages of secondary neovascular glaucoma by gonioscopy, ultrasound biomicroscopy and optical coherence tomography. There were shown the criteria of the anatomic-topographic changes, which are determined in each of the above methods. 34 patients (38 eyes) with secondary neovascular glaucoma in various stages of its development were examined. There were revealed possibilities of using different diagnostic techniques according to the stages of the neovascular process. A possibility of each of the techniques in the presence of certain clinical and morphological changes characteristic for different stages of the disease was substantiated.

\section{Удк: 617.741-004.1:616.379-008.64-089.168-073}

\section{СРАВНЕНИЕ ОТДАЛЕННЫХ РЕЗУЛЬТАТОВ ФАКОЭМУЛЬСИФИКАЦИИ КАТАРАКТЫ У БОЛЬНЫХ САХАРНЫМ ДИАБЕТОМ ІІ ТИПА (по данным оптической когерентной томографии)}

\author{
К. В. Мартопляс, с. н. С., М. П. Кульбида, М. н. С., \\ С. К. Дмитриев, д-р мед. наук, с. н. с., Е. И. Кондратьева, О. В. Левтюх, врачи \\ ГУ«Институт глазных болезней и тканевой терапии им. В. П. Филатова НАМН Украины»
}

\begin{abstract}
Вивчали віддалений (12 міс.) вплив різних методів екстракції ускладненої катаракти на товщину макулярної ділянки сітківки, (за даними оптичної когерентної томографіі) у 64 пацієнтів (64 ока) хворих на иукровий діабет II типу із щільністю ядер II та III ступеня. Встановлено, що проведення гідромоніторної емульсифікації «АqиаLаsе» не викликає змін у товщині сітківки на першу добу, протягом першого місяия та 12 міс. після операції у порівнянні із традиційною факоемульсифікацією.
\end{abstract}

Ключевые слова: осложненная катаракта, УЗ-факоэмульсификация, гидромониторная эмульсификация, сахарный диабет II типа, макулярный отек, оптическая когерентная томография.

Ключові слова: ускладнена катаракта, УЗ -факоемульсифікація, гідромоніторна емульсифікація, цукровий діабет II типу, макулярний набряк, оптична когерентна томографія.

Введение. Существующие на сегодняшний день способы экстракции катаракты (ЭК) делятся на ультразвуковые [13], механические [9], лазерные [2] и при помощи гидроколебаний $[8,11]$. В настоящее время большая часть операций экстракции катаракты выполняется с использованием ультразвуковой факоэмульсификации (Уз-ФЭ) и гидромониторной эмульсификации «AquaLase», при которой хрусталик разрушается и удаляется из глаза с помощью струи воды [12].

Известно, что при Уз-ФЭ отмечаются механическое и тепловое воздействия, оказывающие негативное влияние на ткани как переднего, так и заднего отдела глаза. Именно эти данные, полученные путём анализа отдалённых результатов лечения пациентов методом Уз-ФЭ, остаются противоречивыми.

Кроме того, настоящий научный и практический интерес представляет собой возможность сравнительного анализа повреждающего действия различных способов ЭК на толщину макулярной области сетчатки (ТМОС) [1, 2].

Необходимо отметить, что достаточно чётких данных относительно развития макулярного отека (МО) у больных СД ІІ типа после ЭК в литературе мало, поскольку количество пациентов в выборке было незначительным, а наблюдение за ними недостаточно длительным $[4,14]$.

Принимая во внимание тот факт, что МО остаётся одной из главных причин снижения остроты зрения $(\mathrm{O} 3)$ после ЭК с имплантацией интраокулярных линз, целью нашей работы явилось оценить характер влияния сравниваемых методов ЭК у пациентов с СД II типа на динамику остроты зрения и толщину макулярной области сетчатки оперированных глаз в отдалённом послеоперационном периоде.

(с К. В. Мартопляс, М. П. Кульбида, С. К. Дмитриев, Е. И. Кондратьева, О. В. Левтюх, 2011 
МАТЕРИАЛ И МЕТОДЫ. Под нашим наблюдением находились 64 пациента (64 глаза) с диагнозом диабетическая ретинопатия (ДР), осложненная катаракта. Период наблюдения составил 12 месяцев. Среди обследуемых больных лёгкая степень СД была у 17 (26,6 \%), средняя у 47 $(73,4 \%)$. Непролиферативная стадия ДР была диагностирована у 38 больных (59,4\%), а препролиферативная ДР у $26(40,6 \%)$. Средний возраст пациентов составил от 22 до 77 лет $(\mathrm{M}=57,5 \pm \mathrm{SD} 13,4)$, средний «стаж» диабета колебался от 2 до 27 лет $(M=11,6 \pm S D$ 6,5) лет. На 46 глазах была катаракта со II степенью, а на 18 глазах - с III степенью плотности ядра по Buratto.

Больные были разделены на две группы по методу хирургического лечения катаракты:

- в I группу (n=41) вошли больные, оперированные на факоэмульсификаторе «Infinity Vision System» фирмы «Alcon Inc.»;

- во II группу (n=23) - вошли больные, оперированные по методике гидромониторной эмульсификации «AquaLase» на этом же приборе.

Для количественной оценки У - энергии использовали показатели прибора «Infiniti» (C. D. Е.). Так, средние значения C. D.E. для ядер II степени плотности составили $8,80 \pm 4,62$, для ядер III степени плотности 18,8 $\pm 9,50$.

Среднее значение «АquаTime» (время использования струи жидкости) у больных, оперированных по методике «AquaLase», составило - $(2,41 \pm 1,43)$ минут. Средняя мощность «AquaPower» равнялась $(35,7 \pm 15,2) \%$ [7].

Во всех случаях были имплантированы гибкие ИОЛ.

Измерение морфометрических показателей центральной области сетчатки выполняли методом оптической когерентной томографии (OKT) на томографе «Stratus OCT 3000» фирмы «Carl Zeiss Meditec Inc.». Остроту зрения проверяли по таблице Головина - Сивцева с наилучшей коррекцией.

Результаты измерений подвергали статистической обработке, для классификации случаев по совокупности данных инструментальных измерений применили кластерный анализ [10].

РЕЗУЛЬТАТЫ И ИХ ОБСУЖДЕНИЕ. В Ходе исследования была изучена степень изменения ТМОС (по данным ОКТ) в зависимости от вида факоэмульсификации. Как было установлено ранее [6] у больных СД II типа, оперированных по методу «AquaLase», в первые два дня после операции наблюдаются слабые разнонаправленные и статистически незначимые изменения толщины сетчатки. Напротив, после Уз-ФЭ в эти же сроки (1-2 дня) выявлено статистически значимое уменьшение толщины всех секторов На 30-е сутки после операции Уз-ФЭ толщина секторов значимо увеличивается (табл. 1), что может свидетельствовать о развитии МО. К этому же сроку наблюдения у пациентов, оперированных методом «AquaLase», наблюдается статистически значимое уменьшение толщины фовеа и внутренних секторов, а также сокращение объёма макулярной сетчатки (V MC) в

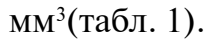

Динамика изменений толщины сетчатки в фовеа и фовеоле в течение 12 месяцев после «AquaLase» представлена на рис. 1.
Линейная интерполяция данных в интервале 30 дней - 12 месяцев после гидромониторной факоэмульсификации показала, что толщина фовеолы $(179,8 \pm 7,3)$ мкм приблизительно равна исходному уровню до операции 179,6士12,1. О возращении показателей ТМОС к первоначальному уровню спустя 6 месяцев наблюдения указывают также как отечественные [5], так и зарубежные авторы [12]. На тот же момент времени - 6 месяцев - можно наблюдать лишь значительное истончение сетчатки в фовеа - на 20,7 мкм. Установлено, что только к 12-му месяцу утолщение сетчатки в фовеоле продолжается, а толщина сетчатки в фовеа стабилизируется.

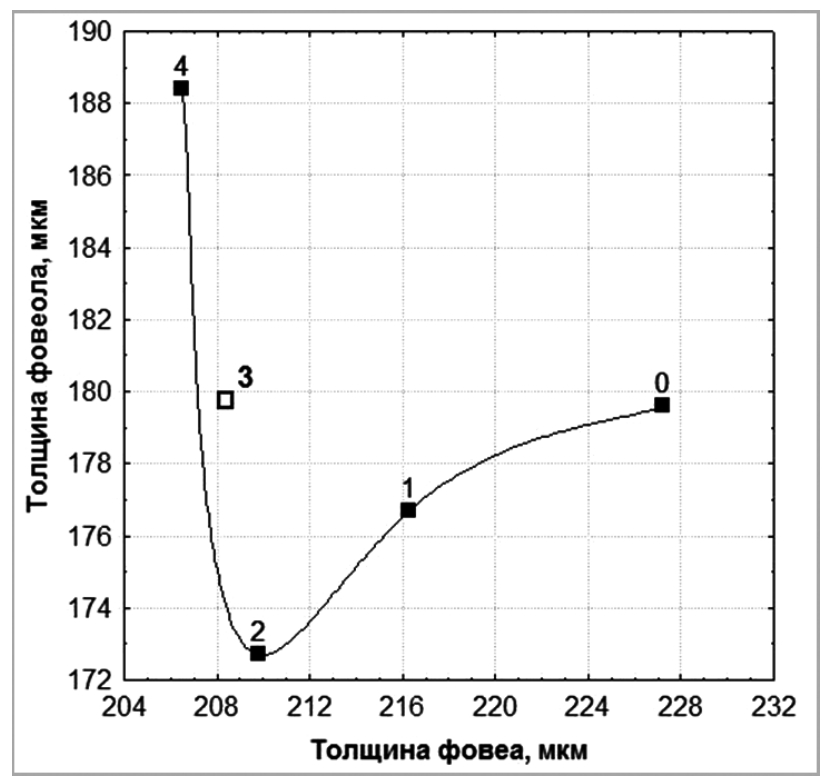

Рис. 1. Совместная динамика пары средних значений толщины сетчатки в фовеа и фовеола после операции «AquaLase»: 0 - до операции; 1 - через 2 дня; 2 - через 30 дней; 3 - через 6 месяцев (интерполяция); 4 - через 12 месяцев

Спустя 12 месяцев после «AquaLase» только у 7 $(30,4 \%)$ пациентов сохраняется слабое утолщение сетчатки в фовеа по сравнению с начальным значением до операции, у остальных 16 (69,6 \%) пациентов наблюдается снижение этого показателя до значений предоперационного уровня. В этот же срок наблюдения после Уз-ФЭ у 37 (88,1 \%) пациентов наблюдается выраженное увеличение толщины сетчатки в фовеа, у 3 (7,1 \%) пациентов отмечено отсутствие изменений, а у 2 (4,8 \%) пациентов уменьшение толщины сетчатки фовеа по сравнению с начальным значением до операции (табл. 2). Морфометрические показатели толщины сетчатки всех секторов по данным ОКТ после Уз-ФЭ статистически значимо превышают таковую после «AquaLase» (тест Уилкоксона, уровень значимости $\mathrm{p}<0,05$ - см. табл. 2). Как видно из данных, представленных в таблице 2, после Уз-ФЭ чаще всего развивается стойкое утолщение макулярной области сетчатки. 
Таким образом, полученные данные позволили сделать вывод о преимуществе «AquaLase» перед традиционной Уз-ФЭ, которое заключается в минимизации реакции макулярной зоны сетчатки у больных СД II типа. Применение гидромониторной ФЭ сопровождается менее вы- раженными колебаниями в степени утолщения сетчатки в фовеа и фовеоле по сравнению с аналогичными показателями после Уз-ФЭ (табл.1). Напротив, после Уз-ФЭ в подавляющем числе случаев ТМОС увеличивается в фовеа и фовеоле (табл. 2).

Таблица 1

Динамика изменений толщины макулярной области сетчатки (мкм) до и после гидромониторной эмульсификации «AquaLase» у больных СД II типа*

\begin{tabular}{|c|c|c|c|c|}
\hline \multirow{2}{*}{ Показатель } & \multirow{2}{*}{$\begin{array}{c}\text { До операции } \\
\mathrm{n}=23\end{array}$} & \multicolumn{3}{|c|}{ После операции } \\
\hline & & 2 сутки & 30 сутки & 12 месяцев \\
\hline Верхне-наружный & $244,5 \pm 13,5$ b & $240,7 \pm 9,2 \mathbf{b}$ & $234,1 \pm 7,1 \mathbf{b}$ & $222,3 \pm 6,2 \mathbf{a}$ \\
\hline Наружный темпоральный & $228,7 \pm 11,2 \mathbf{b}$ & $225,6 \pm 9,9 \mathbf{b}$ & $222,3 \pm 8,7 \mathbf{a b}$ & $212,5 \pm 5,9 \mathbf{a}$ \\
\hline Нижне-наружный & $231,9 \pm 8,5 \mathbf{b}$ & $227,5 \pm 7,8 \mathbf{b}$ & $229,3 \pm 9,1 \mathbf{b}$ & $216,2 \pm 4,9 \mathbf{a}$ \\
\hline Наружный назальный & $251,1 \pm 11,5 \mathbf{b}$ & $247,2 \pm 8,2 \mathbf{b}$ & $247,2 \pm 11,0 \mathbf{a b}$ & $234,4 \pm 7,5 \mathbf{a}$ \\
\hline Верхне-внутренний & $268,5 \pm 15,8 \mathbf{a}$ & $277,8 \pm 9,0 \mathbf{a}$ & $269,7 \pm 5,6 \mathbf{a}$ & $267,7 \pm 7,2 \mathbf{a}$ \\
\hline Внутренний темпоральный & $275,2 \pm 11,1 \mathbf{b}$ & $269,9 \pm 9,0 \mathbf{a b}$ & $260,6 \pm 7,9 \mathbf{a}$ & $260,2 \pm 8,7 \mathbf{a}$ \\
\hline Нижне-внутренний & $272,3 \pm 7,4 \mathbf{a}$ & $273,4 \pm 7,3 \mathbf{a}$ & $266,1 \pm 8,6 \mathbf{a}$ & $264,7 \pm 7,3 \mathbf{a}$ \\
\hline Внутренний назальный & $276,4 \pm 10,5 \mathbf{b}$ & $273,5 \pm 9,5 \mathbf{a b}$ & $268,2 \pm 8,0 \mathbf{a}$ & $269,2 \pm 7,3 \mathbf{a}$ \\
\hline Фовеа & $227,2 \pm 15,8 \mathbf{b}$ & $216,3 \pm 12,7 \mathbf{a b}$ & $209,8 \pm 10,1$ b & $206,5 \pm 7,6 \mathbf{a}$ \\
\hline Фовеола & $179,6 \pm 12,1 \mathbf{a b}$ & $176,7 \pm 13,0 \mathbf{a b}$ & $172,7 \pm 10,0 \mathbf{a}$ & $188,4 \pm 2,7 \mathbf{b}$ \\
\hline Total Macular Volume $\left(\mathrm{MM}^{3}\right)$ & $7,00 \pm 0,25 \mathbf{a}$ & $6,85 \pm 0,20 \mathbf{a}$ & $6,71 \pm 0,19 \mathbf{a}$ & $6,67 \pm 0,14 \mathbf{a}$ \\
\hline
\end{tabular}

* - $\overline{\mathrm{X}}+\mathrm{t}_{0,05} \mathrm{~S}-$ среднее значение \pm доверительный полуинтервал среднего значения; одинаковые литеры в ячейках таблицы означают незначимость различия соответствующих средних значений по непараметрическому тесту Уилкоксона при уровне значимости $\mathrm{p}=0,05$ - выполнены все попарные сравнения по отдельности.

Таблица 2

Толщина макулярной области сетчатки до и после ультразвуковой факоэмульсификации у больных СД ІІ типа (мкм)

\begin{tabular}{|c|c|c|c|c|}
\hline \multirow{2}{*}{ Показатель } & \multirow{2}{*}{$\begin{array}{c}\text { До операции } \\
n=41\end{array}$} & \multicolumn{3}{|c|}{ После операции** } \\
\hline & & 2 сутки & 30 сутки & 12 мес. \\
\hline Верхне-наружный & $246,1 \pm 9,2 \mathbf{a b}$ & $242,2 \pm 8,6 \mathbf{a}$ & $257,7 \pm 12,1 \mathbf{b}$ & $323,5 \pm 7,7 \mathbf{c}$ \\
\hline Наружный темпоральный & $236,6 \pm 9,4 \mathbf{b}$ & $226,3 \pm 8,9 \mathbf{a}$ & $241,5 \pm 11,8 \mathbf{b}$ & $309,2 \pm 7,9 \mathbf{c}$ \\
\hline Нижне-наружный & $244,6 \pm 10,5$ b & $233,1 \pm 8,5 \mathbf{a}$ & $240,4 \pm 9,9 \mathbf{a b}$ & $313,4 \pm 9,8 \mathbf{c}$ \\
\hline Наружный назальный & $248,5 \pm 8,2 \mathbf{a b}$ & $246,9 \pm 9,3 \mathbf{a}$ & $260,3 \pm 10,7 \mathbf{b}$ & $310,5 \pm 9,6 \mathrm{c}$ \\
\hline Верхне-внутренний & $269,5 \pm 6,8 \mathbf{b}$ & $262,1 \pm 6,7 \mathbf{a}$ & $268,5 \pm 8,0$ ab & $316,1 \pm 9,9 \mathrm{c}$ \\
\hline Внутренний темпоральный & $264,4 \pm 7,9 \mathbf{b}$ & $257,9 \pm 7,6 \mathbf{a}$ & $264,2 \pm 8,4 \mathbf{a b}$ & $305,7 \pm 9,2 \mathbf{c}$ \\
\hline Нижне-внутренний & $267,6 \pm 7,2 \mathbf{b}$ & $258,9 \pm 6,8 \mathbf{a}$ & $268,4 \pm 7,0 \mathbf{b}$ & $301,9 \pm 7,5 \mathbf{c}$ \\
\hline Внутренний назальный & $260,0 \pm 6,7 \mathbf{a}$ & $258,0 \pm 6,2 \mathbf{a}$ & $263,7 \pm 6,6 \mathbf{a}$ & $297,5 \pm 7,4 \mathbf{b}$ \\
\hline Фовеа & $201,7 \pm 7,9 \mathbf{b}$ & $195,4 \pm 7,7 \mathbf{a}$ & $216,1 \pm 10,0 \mathbf{c}$ & $272,4 \pm 9,5 \mathbf{d}$ \\
\hline Фовеола & $181,8 \pm 9,2 \mathbf{b}$ & $173,5 \pm 10,0 \mathbf{a}$ & $183,9 \pm 8,9 \mathbf{b}$ & $221,0 \pm 4,9 \mathbf{c}$ \\
\hline Total Macular Volume $\left(\mathrm{MM}^{3}\right)$ & $6,75 \pm 0,20 \mathbf{b}$ & $6,57 \pm 0,21 \mathbf{a}$ & $6,90 \pm 0,21 \mathbf{b}$ & $8,18 \pm 0,31 \mathbf{c}$ \\
\hline
\end{tabular}

* - как к табл. 1

Как показали отдалённые результаты обследования пациентов, степень восстановления О3 оперированного глаза подвержена значительным колебаниям. Несмотря на стандартизированный подход при проведении операций, разработанный в отделе патологии хрусталика ГУ Институт глазных болезней и тканевой терапии им.В. П. Филатова АМН Украины», при обеих хирургических методиках отмечены случаи неудовлетворительных отдалённых результатов. Поэтому для оценки эффективности хирургического лечения мы воспользовались совокупностью клинических признаков, позволивших нам разделить пациентов на две группы: А - положительный результат и Б отрицательный результат.

Положительный результат: улучшение О3 оперированного глаза, отсутствие прогрессирования ДРП, ТСМО в фовеоле $\leq(196,9 \pm 6,5)$ мкм, относительная стабилизация уровня глюкозы крови - не более $(8,2 \pm 1,7)$ ммоль/л, уровень гликозилированного гемоглобина HbA1 7,7-11,2\%.

Отрицательный результат: О3 не ухудшилась после операции или ухудшилась, прогрессирование ДРП, рубеоз радужки, рецидивирующие гифемы, вторичная глаукома, утолщение ТСМО > $(200,9 \pm 7,3)$ мкм, декомпенсация уровня глюкозы 
крови - $(12,2 \pm 2,8)$ ммоль/л, (колебание уровня HbA1 от $10,4 \%$ до $18 \%)$.

Таким образом, полученные результаты являются поводом для проведения дальнейших исследований.

\section{ВЫВоды}

1. Выявлено достоверное увеличение толщины макулярной области сетчатки пациентов, по данным ОКТ, через 12 месяцев после Уз-ФЭ.

2. Гидромониторная эмульсификация «AquaLase» не приводит к изменениям морфометрических показателей ТМОС в фовеа и фовеоле в эти же сроки наблюдения.

\section{ЛИТЕРАТУРА}

1. Аветисов С. Э. Сравнительная оценка влияния гидромониторной факофрагментации и ультразвуковой факоэмульсификации на морфометрические параметры центральной области сетчатки / С. Э. Аветисов, Ю. Н. Мамиконян, Ю. Н. Юсеф [и др.] // Вестн. офтальмол. - 2008. - № 1. - С. 8-11.

2. Веселовская 3. Ф. Катаракта / : [монография] / 3. Ф. Веселовская, Н. Блюменталь, Н. Ф. Боброва. К. : Книга плюс, 2002. - 208 с.

3. Галоян Н. С. Влияние хирургической травмы на морфофункциональное состояние центральной зоны сетчатки при различных способах современной хирургии катаракты : автореф. дис. на соискание ученой степени канд. мед. наук : спец. 14.00.08 «Глазные болезни» / Н. С. Галоян. - М., 2004. - 25 c.

4. Егоров В. В. Клинико - морфометрические особенности изменений макулы у больных сахарным диабетом после факоэмульсификации катаракты / В. В. Егоров, А. В. Егорова, Г. П. Смолякова, Е. Л. Сорокин // Вестн. офтальмол. - 2008. - № 4. - С. 22-25.

5. Капшук Н. И. Морфометрические особенности центральной области сетчатки (по данным ОКТ) после гидромониторной и ультразвуковой факоэмульсификации у больных возрастной катарактой и маку- лярной дегенерацией / Н. И. Капшук // Офтальмол. журн. - 2010. - № 5. - С. 42-45.

6. Науменко В. А. Характер изменения толщины макулярной области сетчатки (по данным оптической когерентной томографии) у больных сахарным диабетом II типа после хирургического лечения катаракты / В. А. Науменко, К. В. Мартопляс, С. К. Дмитриев [и др.] // Офтальмол. журн. - 2010. - № 4. - С. 4-7.

7. Пат. № 53410 Україна А61F 9/00. Спосіб екстракції ускладненої катаракти у хорих на цукровий діабет II типу / Науменко Володимир Олександрович, Мартопляс Костянтин Віталійович, Дмитрієв Сергій Костянтинович; заявник і власник ДУ «Інститут очних хвороб і тканинної терапії ім.В. П. Філатова АМН України». - № u2010 02828; заявл. 12.03.10.

8. Темиров Н. Э. Гидромониторная факофрагментация и витректомия (теоретическое, экспериментальное, клиническое обоснование) / Н. Э. Темиров // Вестн. офтальмол. - 1982. - № 2. - С. 20-25.

9. Федоров С. Н. Прогнозирование функциональных результатов экстракции катаракты у больных сахарным диабетом / С. Н. Федоров, Э. В. Егорова, И. Э. Иошин [и др.] // Офтальмохирургия. - 1992. - № 2. С. $15-19$.

10. Электронный учебник по статистике. - M.: StatSoft Inc., 2001. - [Электронный ресурс]. - Режим доступа: http://statsoft.ru/home/textbook/contents.html. Дата доступа: 23.02.2010 г.

11. Barsam A. AquaLase shows trend toward less foveal thickening in diabetic patients / A. Barsam // J. Cataract. Refract. Surg. - 2009. - Vol. 25. - № 3. - P. 563-565.

12. Hildago - Simon A. AquaLase system viable for small incision cataract removal / A. Hildago - Simon // XX ESCRS Congress : abstract book. - 2009. - P. 167.

13. Kelman C. D. Phaco - emulsification and aspiration / C. D. Kelman // Am. J. Ophthalmol. - 1969. - Vol. 67. P. 464-477.

14. Wang J. Development and progression of diabetic retinopathy 12 months after phacoemulsification cataract surgery / J. Wang // Ophthalmology. - 2009. - Vol. 10, № 3. P. 1016.

Поступила 26.01.2011

Рецензент ст.науч.сотр., к.М.н. В. Я. Усов

\title{
COMPARISON OF THE LONG-TERM RESULTS OF CATARACT PHACOEMULSIFICATION IN PA- TIENTS WITH DIABETES MELLITUS OF II TYPE (ACCORDING TO THE DATA OF OPTIC COHER- ENT TOMOGRAPHY)
}

\author{
Martoplyas K. V., Dmitriev S. K., Kulbida M. P., Kondratieva E. I., Levtyukh O. V.
} Odessa, Ukraine

The influence of different methods of complicated cataract extraction on the retinal thickness (according to OCT ) was studied in 64 patients (64 eyes) with DM of II type (nuclear density of II and III degrees). It is established that there are no changes in the retinal thickness after AquaLase method on the $1^{\text {st }}$ day after cataract phacoemulsification as well as after 1 month -12 months of follow- up in comparison with traditional phacoemulsification. 